\title{
Perfil sorológico para circovírus suíno tipo 2 em granjas comerciais de suínos no Brasil
}

\author{
[Serological profiles to porcine circovirus type 2 antibodies in Brazil] \\ C.N. Barbosa ${ }^{1}$, Z.I.P. Lobato ${ }^{2}$, N.R.S. Martins ${ }^{2}$, E. F. Nascimento ${ }^{2}$ \\ ${ }^{1}$ Médica veterinária autônoma - Barbacena, MG \\ ${ }^{2}$ Escola de Veterinária - UFMG - Belo Horizonte, MG
}

\begin{abstract}
RESUMO
A técnica de imunoperoxidase em monocamada de células (IPMC) para demonstração de anticorpos contra o circovírus suíno tipo 2 (CVS2) foi empregada para a investigação sorológica em oito granjas de suínos destinadas à produção comercial. Das 240 amostras de soros testadas, 229 (95,4\%) foram reagentes com títulos que variaram de 20 até 10.240. Títulos de anticorpos foram detectados nas faixas etárias de duas a três semanas até animais acima de 24 semanas e encontrados em granjas com e sem a síndrome multissistêmica do definhamento (SMD). A média dos títulos de anticorpos revelou diferenças estatísticas $(\mathrm{P}<0,05)$ nas faixas etárias de 11 a 13 e 14 a 22 semanas nos animais oriundos de granjas com e sem a SMD. Os resultados refletem a importância de conhecer o perfil sorológico do rebanho e assegurar a implantação de um efetivo cronograma de vacinação contra o CVS2.
\end{abstract}

Palavras-chave: suíno, circovírus suíno tipo 2, CVS2, síndrome multissistêmica do definhamento, SMD, sorologia

\begin{abstract}
The immunoperoxidase in monolayer cells (IPMC) technique for the demonstration of antibodies against type 2 porcine circovirus (PCV2) was used for the serological investigation in eight industrial swine farms. Out of the 240 tested sera, 229 (95,4\%) were reactive with titers which varied from 20 up to 10.240. Titers of antibodies were detected in pigs from two to three weeks of age up to above 24 weeks of age, and were observed in farms with and without clinical signs indicative of the post-weaning multisystemic wasting syndrome (PMWS). Analysing the mean titers, statistical differences $(P<0.05)$ were evidentiated in two age intervals, of 11 to 13 and 14 to 22 weeks of age. The results indicate the importance of determining the serological profiles of commercial swine herds, in order to enable the implantation of effective hygiene and vaccination protocols for PCV2 prevention.
\end{abstract}

Keywords: swine, PCV2, porcine circovirus type 2, PMWS, post-weaning multisystemic wasting, serology

\section{INTRODUÇ̃̃O}

Nos últimos anos, houve grande desenvolvimento no sistema de produção de suínos, principalmente quanto à genética, nutrição, manejo e sanidade. Os animais passaram a ser criados de forma cada vez mais intensiva, os rebanhos ficaram maiores $\mathrm{e}$, conseqüentemente, com maior predisposição às doenças, dentre elas, a síndrome multissistêmica do definhamento (SMD), associada ao circovírus suíno tipo 2 (CVS2).

A SMD acomete suídeos, principalmente de seis a 12 semanas de vida, e os sinais clínicos mais comuns incluem emagrecimento progressivo, distúrbios respiratórios e diarréia. As lesões macroscópicas são variáveis, sendo mais freqüentes a linfoadenopatia regional ou generalizada e a pneumonia intersticial. As

Recebido em 29 de outubro de 2007

Aceito em 19 de maio de 2007

E-mail: claranbarbosa@yahoo.com

Apoio: CNPq/FAPEMIG 
lesões histopatológicas, especialmente em tecidos linfóides, são representadas por diminuição do número de linfócitos, seguida de proliferação de histiócitos, formação de células gigantes multinucleadas e, ocasionalmente, presença de corpúsculos de inclusão intracitoplasmáticos (Segalés et al., 2005).

O CVS2 é um vírus pequeno, possui genoma DNA circular, não envelopado, estável ao meio ambiente e resistente à maioria dos desinfetantes comuns. Trata-se de um integrante da família Circoviridae, que atualmente é composta por dois gêneros: Circovírus e Girovírus, que incluem respectivamente o CVS2 e o vírus da anemia das galinhas (Tischer et al., 1982; Todd, 2000; Royer, 2001).

Os prejuízos decorrentes da síndrome nos plantéis afetados são substanciais para a indústria suinícola. Entre eles, os elevados índices de morbidade, os gastos com antibióticos, o declínio das taxas de crescimento e a queda na conversão alimentar, que elevam os números de animais debilitados e / ou refugos (Segalés et al., 2005; Morés et al., 2007).

Dados sorológicos indicam que a infecção pelo CVS2 pode estar amplamente distribuída entre a população suína mundial. Em diversos países europeus, índices próximos de 100\% dos rebanhos são reagentes por sorologia, indicando que a infecção pelo CVS2 é disseminada e que pode ocorrer em rebanhos afetados e não afetados pela SMD (Larochelle et al., 2003).

O objetivo deste trabalho foi investigar o perfil sorológico para o CVS2 em diferentes granjas destinadas à produção comercial de suínos.

\section{MATERIAL E MÉTODOS}

Entre outubro de 2003 a julho de 2004, foram estudadas oito granjas suinícolas, sendo quatro localizadas no estado de Minas Gerais (MG), três em Santa Catarina (SC) e uma no Rio Grande do Sul (RS). Os critérios adotados para a inclusão do rebanho no estudo foram os seguintes: a permissão e o apoio do proprietário / veterinário / técnico para a realização da coleta do material; o rebanho ser constituído no mínimo de 300 matrizes com ciclo completo de produção de suínos destinados ao abate; ser classificado de suspeito e não suspeito da ocorrência da SMD, com base no histórico clínico e patológico do plantel (Tab.1).

Foram colhidas 240 amostras de sangue de suínos das oito granjas, identificadas de I a VIII, sendo 30 amostras de cada granja e cinco em cada fase de produção, definidas por idades expressas em semanas: duas a três; quatro a seis; sete a $10 ; 11$ a $13 ; 14$ a 22 e $>24$ semanas.

Os soros foram analisados pela técnica de imunoperoxidase em monocamada de célula (IPMC), desenvolvida no Laboratório Nacional Agropecuário/Minas Gerais do Ministério da Agricultura, Pecuária e Abastecimento (LANAGRO/MG-MAPA) (Balasch et al., 1999; Rodríguez-Arrioja et al., 2003). As microplacas impregnadas com antígeno viral, mantidas a $-20^{\circ} \mathrm{C}$, foram descongeladas à temperatura ambiente, lavadas três vezes com $0,15 \mathrm{M}$ de solução salina tamponada, $\mathrm{pH} 7,4$ contendo $0,05 \%$ de Tween 20 (PBS-Tw20) e secas. Os soros a serem testados foram diluídos a partir de 1:20 até 1:10.240 e adicionados, em duplicata, $70 \mu \mathrm{l}$ às cavidades correspondentes nas microplacas e incubadas a $37^{\circ} \mathrm{C}$ por $60 \mathrm{~min}$. Após três lavagens com PBSTw20, foram adicionados $100 \mu 1$ de anticorpo secundário anti-IgG de suíno, conjugado à enzima peroxidase, na diluição de 1:2.000 em toda a microplaca e procedida à incubação, lavagem e secagem, como descrito anteriormente. A seguir foi adicionada a solução de substrato $\mathrm{AEC}^{1}$, diluída em tampão acetato de sódio a $0,05 \mathrm{M}$ e mantida por 10 min.à temperatura ambiente. Após esse período, a reação enzimática foi interrompida por adição em toda a microplaca de acetato de sódio a $0,05 \mathrm{M}$. A leitura foi realizada em microscópio de luz invertida com o aumento de 100x. Para interpretação, os resultados sorológicos foram classificados como reagentes e não reagentes. Os reagentes foram agrupados de acordo com o título: baixo, de 20 a 160; médio, 320 até 2560 e alto, $>$ de 5120 .

A técnica de imunoistoquímica (IHQ) foi realizada como descrita previamente por Chianini et al., 2001 e Faccini et al., 2005.

A análise de variância foi realizada a partir da média geométrica dos títulos de anticorpos após a transformação logarítmica $[\log 2($ Tit +1$)]$. As médias foram comparadas pelo teste Duncan considerandose $\mathrm{P}<0,05$ como significativo (Sampaio, 1998).

${ }^{1}$ Aminoetil carbazol - Sigma Chemical, St. Louis, EUA. 
Perfil sorológico para circovírus...

Tabela 1. Identificação e informações das oito granjas estudadas e dos animais necropsiados

\begin{tabular}{|c|c|c|c|c|c|c|c|}
\hline Granja & Estado & $\begin{array}{l}\text { Número } \\
\text { de } \\
\text { matrizes }\end{array}$ & $\begin{array}{l}\text { Índice } \\
\text { de } \\
\text { refugagem }\end{array}$ & $\begin{array}{l}\text { Indice } \\
\text { de } \\
\text { mortalidade }\end{array}$ & Sinais clínicos & $\begin{array}{l}\text { Necropsia } \\
\text { idade } \\
\text { (dias) }\end{array}$ & $\begin{array}{c}\text { Resultado } \\
\text { da } \\
\text { IHQ }\end{array}$ \\
\hline 1 & $\mathrm{SC}$ & 306 & $2 \%$ & $1,5 \%$ a $2 \%$ & $\begin{array}{l}\text { Diarréia na creche } \\
\text { Distúrbios respiratórios }\end{array}$ & $\mathrm{NR} / 78$ & Neg. \\
\hline II & $\mathrm{SC}$ & 550 & 10 a $15 \%$ & $>2,5 \%$ & $\begin{array}{l}\text { Distúrbios respiratórios } \\
\text { Linfoadenopatia } \\
\text { generalizada } \\
\text { Diarréia na creche/recria }\end{array}$ & $\begin{array}{l}\mathrm{R} / 55 \\
\mathrm{R} / 90\end{array}$ & $\begin{array}{l}+ \\
+\end{array}$ \\
\hline (1) III & MG & 470 & 2 a $5 \%$ & $<1 \%$ & $\begin{array}{l}\text { Distúrbios respiratórios } \\
\text { Diarréia na creche }\end{array}$ & $\mathrm{NR} / 68$ & Neg. \\
\hline IV & MG & 4000 & $>10 \%$ & $>2,5 \%$ & $\begin{array}{l}\text { Distúrbios respiratórios } \\
\text { Diarréia na terminação }\end{array}$ & $\begin{array}{c}\mathrm{R} / 70 \\
\text { (2) } \mathrm{NR} / 50\end{array}$ & $\begin{array}{c}+ \\
\text { Neg. }\end{array}$ \\
\hline (3) $\mathrm{V}$ & MG & 340 & 2 a $5 \%$ & $<1 \%$ & Distúrbios respiratórios & - & - \\
\hline VI & $\mathrm{SC}$ & 1250 & $>10 \%$ & $>2,5 \%$ & $\begin{array}{l}\text { Distúrbios respiratórios } \\
\text { Diarréia na recria } \\
\text { Alterações reprodutivas } \\
\text { Necrose de orelha }\end{array}$ & $\begin{array}{l}\mathrm{R} / 60 \\
\mathrm{NR} / 65\end{array}$ & $\begin{array}{c}+ \\
\text { Neg. }\end{array}$ \\
\hline (1) VII & RS & 2200 & 10 a $15 \%$ & $>2,5 \%$ & $\begin{array}{l}\text { Distúrbios respiratórios } \\
\text { Diarréia na creche }\end{array}$ & $\mathrm{R} / 63$ & + \\
\hline (3) V111 & MG & 400 & 2 a $5 \%$ & $<1 \%$ & $\begin{array}{l}\text { Diarréia / creche } \\
\text { Distúrbios respiratórios / } \\
\text { creche } \\
\text { Alteracões reprodutivas }\end{array}$ & - & - \\
\hline
\end{tabular}

IQR: imunoistoquímica; R: animal refugo; NR: animal não refugo.

$\uparrow$ : Animal encontrado morto;

(1): casos esporádicos de epidermite exsudativa; (2): animal encontrado morto; (3): necropsia não realizada.

\section{RESULTADOS E DISCUSSÃO}

Este é o primeiro estudo dos perfis sorológicos para o CVS2 em rebanhos de suínos realizado no Brasil. Das 240 amostras de soros testadas, 229 $(95,4 \%)$ foram reagentes com títulos que variaram de 20 até 10.240 . Títulos de anticorpos foram detectados nas faixas etárias de duas a três semanas até animais acima de 24 semanas de idade e encontrados em todas as granjas estudadas com e sem a SMD. Os resultados sorológicos estão detalhados na Fig.1.

Observa-se a tendência de declínio dos títulos de anticorpos até níveis mais baixos entre sete a 10 e 11 a 13 semanas de idade e aumento linear, em todas as granjas, com títulos altos nas faixas etárias de 14 a 22 e acima de 24 semanas. O aumento dos títulos de anticorpos, nas granjas II e $\mathrm{V}$, iniciou-se precocemente e foi detectado a partir de sete a 10 semanas. Nas granjas IV e VI, os títulos de anticorpos foram detectados nas faixas etárias de 11 a 13 semanas e 14 a 22 semanas nas granjas I, III, VII e VIII.

A diferenciação na velocidade da queda dos anticorpos, provavelmente de origem materna, seguida por uma soroconversão ativa pode estar relacionada a múltiplas exposições ao vírus durante o ciclo de produção que, por sua vez, estariam associadas às falhas de biosseguridade $\mathrm{e}$ qualidade de manejo adotadas pelas granjas. Os perfis sorológicos encontrados sugerem que a exposição ao CVS2 resulta em infecção dos animais susceptíveis pela queda dos anticorpos passivos, entre quatro a seis e 11 a 13 semanas de idade com a presença do animal refugo, que é a principal manifestação clínica da doença, seguida pelo reaparecimento dos títulos de anticorpos, a partir de 14 semanas de idade. Os resultados são semelhantes aos encontrados por Tischer et al. (1986); Allan (1996). 


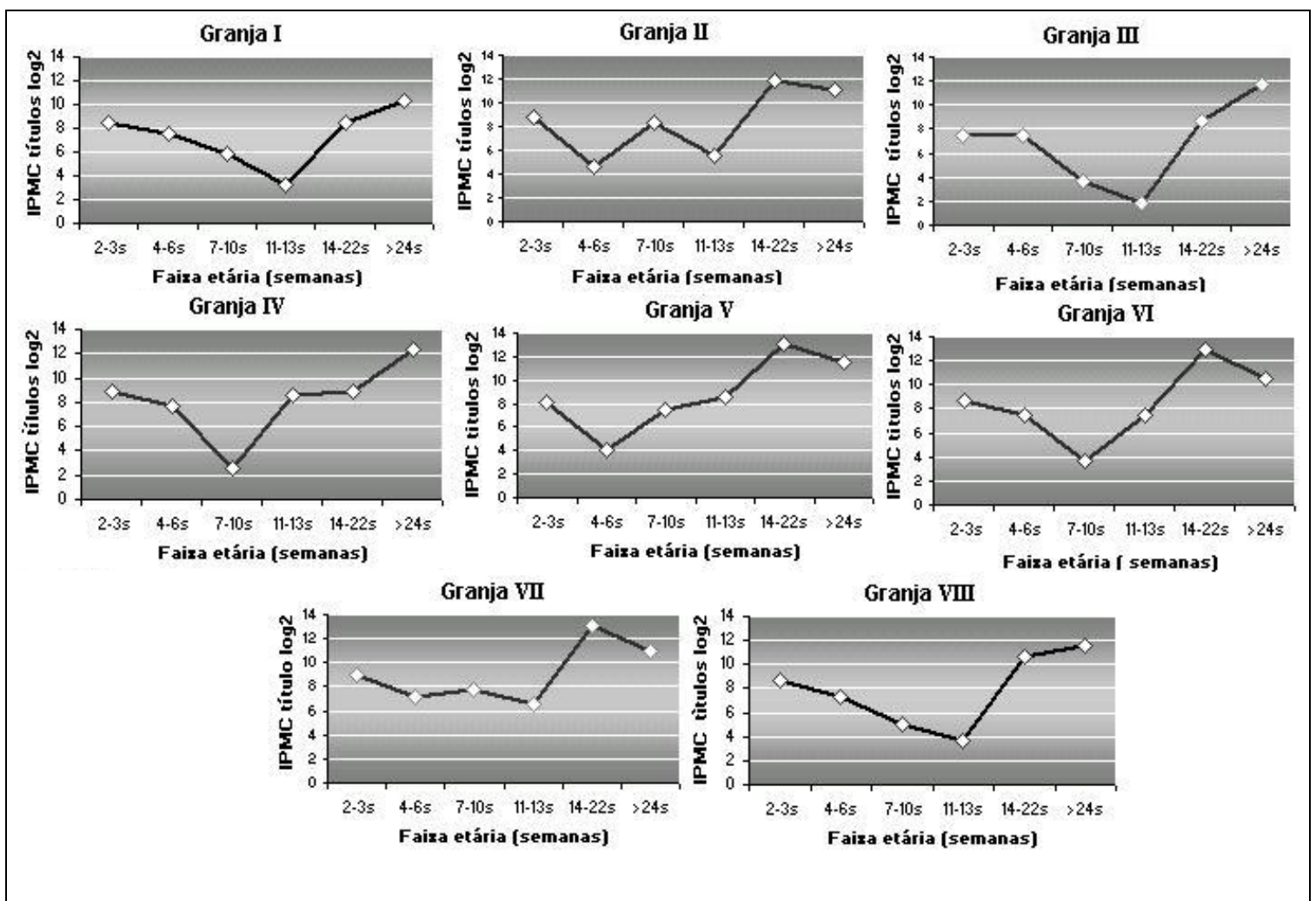

Figura 1. Perfil sorológico obtido nas diferentes faixas etárias do ciclo de produção, nas oito granjas de suínos com e sem a SMD. Representação das médias geométricas dos títulos de anticorpos após a transformação logarítmica $[\log 2($ Tit +1$)]$.

Os animais necropsiados nas granjas I, II, III, IV, VI e VII apresentaram títulos de anticorpos para o CVS2 que variavam de baixo a alto. Os títulos baixos relacionaram-se à ausência ou fraca marcação do antígeno viral pesquisado pela técnica de IHQ, enquanto os títulos médios a altos forneceram amostras de tecidos com grande marcação do antígeno viral demonstrado pela técnica de IHQ. Infere-se que os valores de títulos de anticorpos médios a altos para o CVS2 podem coexistir com a presença dos sinais clínicos característicos da síndrome e a presença do antígeno viral nos tecidos. Estes resultados são similares aos encontrados por McNeilly et al. (1999) e Rodríguez-Arrioja et al. (2003), que correlacionaram altos títulos de anticorpos para o CVS2 com grande quantidade de antígeno viral nas lesões histopatológicas, alterações macroscópicas e sinais clínicos sugestivos da SMD.

A determinação da ocorrência da SMD em uma granja é tarefa difícil, devido às participações de coinfecções que agravam a doença ou modificam os sinais clínicos, mascarando o diagnóstico diferencial. Recomenda-se conjugar pelo menos três fatores: histórico clínico do plantel, presença de achados de necropsia e demonstração do antígeno viral dentro das lesões histopatológicas (Segalés et al., 2005; Fernandes et al., 2006).

Na Tab. 1, observa-se que as granjas II, IV, VI e VII reuniam evidências de ocorrência da síndrome, tais como, altos índices de refugagem $(>10 \%)$ e de mortalidade $(>2,5 \%)$ e diagnóstico positivo no teste de IHQ em animais necropsiados, associados à presença de outros sinais clínicos compatíveis com a SMD (grupo de granjas com SMD). As granjas I, III, V e VIII não apresentaram o somatório de três fatores compatíveis com a presença de SMD (grupo de granjas sem SMD). As médias dos títulos de anticorpos das granjas dos dois grupos, com e sem SMD, estão apresentadas na Fig. 2. 


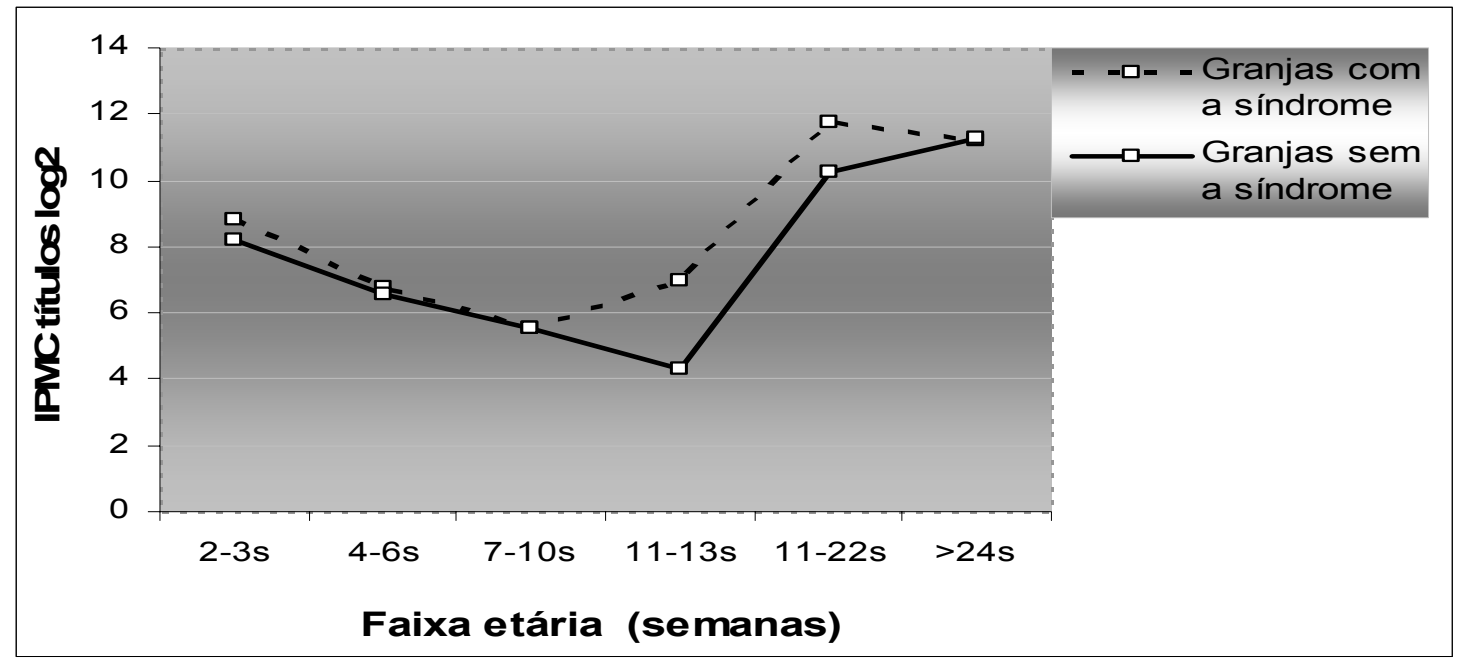

Figura 2. Médias dos títulos de anticorpos nas granjas com e sem da síndrome multissistêmica do definhamento.

Nas granjas com a SMD, houve elevação dos títulos de anticorpos em torno da $11^{\mathrm{a}}$ semana, sugerindo uma infecção precoce, enquanto nas granjas sem a síndrome a elevação dos títulos ocorreu a partir da $14^{\mathrm{a}}$ semana. Este fato é sustentado por Ladekjær et al. (2003) ao verificaram que, em granjas com a SMD, a soroconversão ocorreu mais cedo quando comparadas com granjas sem sinais característicos da síndrome. A infecção pelo CVS2 pode estar disseminada em suínos criados intensivamente sem a ocorrência da forma clínica da SMD (Quintana et al., 2001; Labarque et al., 2001; Rose et al., 2002; Harding, 2004).

Foi verificado que a média de títulos de anticorpos dos animais oriundos de granjas com a SMD e sem a SMD, apresentou diferenças estatísticas $(\mathrm{P}<0,05)$ nas faixas etárias de 11 a 13 e 14 a 22 semanas de idade (Fig. 2). Os resultados obtidos divergem dos estudos de Larochelle et al. (2003), que compararam sete granjas com e sem sinais clínicos da SMD e concluíram que os títulos de anticorpos foram similares em todos os rebanhos analisados.

Nas granjas estudadas, a infecção viral ocorreu endemicamente e o contato dos animais com o vírus, que possui alta resistência ao meio ambiente, pode ter ocorrido desde o nascimento, pois o vírus circulava em todas as faixas etárias. Os resultados obtidos refletem bem a variabilidade da circulação do vírus nas granjas estudadas, o que reforça a necessidade de se conhecer o perfil sorológico da granja e não apenas diagnósticos individuais. Soma-se ao fato que o conhecimento do perfil sorológico dos animais assegura um efetivo cronograma de vacinação contra o CVS2, considerando que a queda de anticorpos passivos pode variar entre os animais e em diferentes granjas. Ressalta-se, ainda, que a análise sorológica aplicada isoladamente não é suficiente para a detecção da SMD no rebanho.

\section{REFERÊNCIAS BIBLIOGRÁFICAS}

ALLAN, G.M. Porcine circovirus: epidemiology and pathogenesis. Pig J., v.37, p.14-19, 1996.

BALALASCH, M.; SEGALÉS, J.; ROSSEL, C. et al. Experimental inoculation of conventional pigs with tissue homogenates from pigs affected with post-weaning multisytemic wasting syndrome. J. Comp. Pathol., v.121, p.139-148, 1999.

CHIANINI, F.; MAJÓ, N.; SEGALÉS, J. et al. Immunohistochemical characterisation of PCV2 associated lesions in lymphoid and nonlymphoid tissues of pigs with natural postweaning multisystemic wasting syndrome (PMWS). Vet. Immunol. Immunopathol., v.82, p.245-255, 2001.

FACCINI, G.S.; GUEDES, R.M.; PESCADOR, C.A. et. al. Diagnóstico histoquímico e imunohistoquímico de enteropatia proliferativa (Lawsonia intracellularis) em suínos. Arq. Bras. Med. Vet. Zootec., v.57, p.569-575, 2005. 
FERNANDES, L.T.; ZANELLA, J.R.C.; SOBESTIANSKY, J. et al. Coinfecção experimental de circovírus suíno tipo 2 (PCV2) isolado no Brasil e parvovírus suíno (PPV) em suínos SPF. Arq. Bras. Med. Vet. Zootec., v.58, p.1-8, 2006.

HARDING, J.C. The clinical expression and emergence of porcine circovirus 2. Vet. Microbiol., v.98, p.131-135, 2004.

LABARQUE， G.G.; NAUWYNCK, H.J.; MESU, A.P. et al. Seroprevalence of porcine circovirus type 1 and 2 the Belgian pig population. Vet. Q., v.22, p.234-236, 2001.

LADEKJÆR-MIKKELSEN, A.S.; BØTNER, A.; NIELSEN, J. et al. Serological profiles in Danish PMWS case and control herds. INTERNATIONAL SYMPOSIUM ON EMERGING AND RE-EMERGING PIG DISEASES, 4., 2003, Rome. Proceedings... Rome, 2003. p.184-185.

LAROCHELLE, R.; MAGAR, R.; D'ALLAIRE, S. Comparative serological and virological study of herds with and without postweaning multisytemic wasting syndrome (PMWS). INTERNATIONAL SYMPOSIUM ON EMERGING AND RE-EMERGING PIG DISEASES, 4., 2003, Rome. Proceedings... Rome, 2003. p.336.

McNEILLY, F.; KENNEDY, S.; MOFFETT, D. et al. A comparison of in situ hybridization and immunohistochemistry for the detection of a new porcine circovirus in formalin-fixed tissues from pigs with post-weaning multisystemic wasting syndrome (PMWS). J. Virol. Meth., v.80, p.123$128,1999$.

MORÉS, N.; AMARAL, A.L.; ZANELLA, J.R.C. et al. Uso do plasma suíno ultrafiltrado na recuperação de leitões com sinais clínicos de circovirose. Arq. Bras. Med. Vet. Zootec., v.59, p.1124-1131, 2007.
QUINTANA, J.; SEGALÉS, J.; ROSELL, C. et al. Clinical and pathological observations of pigs with postweaning multisystemic wasting syndrome. Vet. Rec., v.149, p.357-361, 2001.

RODRÍGUEZ-ARRIOJA, G. M.; SEGALÉS, J.; ROSELL, C. et al. Retrospective study on porcine circovirus type 2 infection in pigs from 1985 to 1997 in Spain. Vet. Med. B Infect. Dis. Vet. Public Health, v.50, p.99-101, 2003.

ROYER, R.L. Susceptibility of prcine crcovirus type 2 to commercial and laboratory disinfectants. J. swine Health Prod., v.9, p.281284, 2001.

ROSE, N.; BLANCHARD, P.; LAUROUR, G. et. al. Post-weaning multisystemic wasting syndrome (PMWS) in France: serological profiles of affected versus non-affected herds and preliminary analytical epidemiology. Pig J., v.50, p.124-134, 2002.

SAMPAIO, I.B.M. Estatística aplicada à experimentação animal. Belo Horizonte: FEPMVZ, 1998. 221p.

SEGALÉS, J.; ALLAN, G.M.; DOMINGO, M. Porcine circovirus diseases. Anim. Health Res. Rev., v.6, p.119-142, 2005.

TISCHER, I.; GELDERBLOM, H.; VETTERMANN, W. et al. A very small porcine virus with circular single-stranded DNA. Nature, v.295, p.64-65, 1982.

TISCHER, I.; MIELDS, W.; WOLFF, D. et al. Studies on epidemiology and pathogenicity of porcine circovirus. Arch. Virol., v.91, p.271-276, 1986.

TODD, D. Circoviruses: immunosuppressive threats to avian species: a review. Avian Pathol., v.29, p.373-394, 2000. 